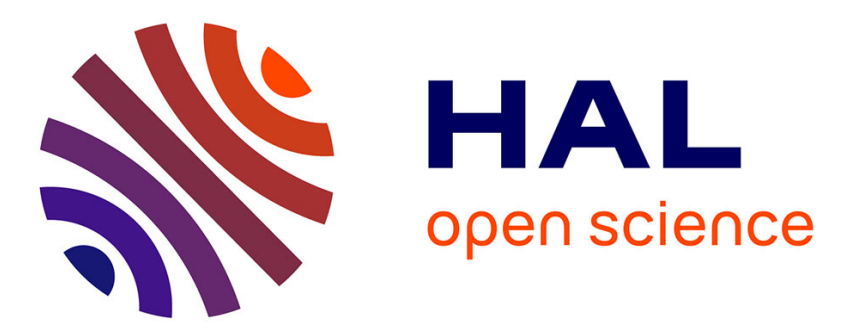

\title{
Water solubility of drug-like molecules with the cubic-plus-association equation of state
}

Fátima L. Mota, António J. Queimada, Simão P. Pinho, Eugénia A. Macedo

\section{To cite this version:}

Fátima L. Mota, António J. Queimada, Simão P. Pinho, Eugénia A. Macedo. Water solubility of drug-like molecules with the cubic-plus-association equation of state. Fluid Phase Equilibria, 2010, 298 (1), pp.75-82. 10.1016/j.fluid.2010.07.004 . hal-01637114

\section{HAL Id: hal-01637114 \\ https://hal.science/hal-01637114}

Submitted on 26 Oct 2018

HAL is a multi-disciplinary open access archive for the deposit and dissemination of scientific research documents, whether they are published or not. The documents may come from teaching and research institutions in France or abroad, or from public or private research centers.
L'archive ouverte pluridisciplinaire HAL, est destinée au dépôt et à la diffusion de documents scientifiques de niveau recherche, publiés ou non, émanant des établissements d'enseignement et de recherche français ou étrangers, des laboratoires publics ou privés. 


\section{Water Solubility of Drug-Like Molecules with the Cubic-

$11{ }^{2}$ LSRE/LCM - Laboratory of Separation and Reaction Engineering, Escola Superior de

12 Tecnologia e Gestão, Instituto Politécnico de Bragança, Campus de Santa Apolónia,

$$
\text { 5301-857 Bragança, Portugal }
$$

$18{ }^{*}$ To whom correspondence should be addressed: ajq@fe.up.pt 


\section{Abstract \\ 2}

3 Although of extreme importance for evaluating the effective therapeutic action, 4 aqueous solubility data involving drug-like molecules are scarce. Thermodynamic models 5 can be used to estimate these solubilities, and different models, namely activity coefficient 6 models, have been applied for that purpose. Still, these frequently cannot describe with 7 accuracy broad temperature and pressure ranges, various solvent compositions or 8 multifunctional molecules.

9 Despite the success of the cubic-plus-association (CPA) equation of state (EoS) in 10 modeling complex systems, it has never been used for modeling the phase equilibria of 11 drug-like molecules, explicitly accounting for the number and nature of associating sites. In 12 this work, aqueous solubilities of different complex solutes, like acetamide, acetanilide, 13 acetylsalicylic acid, adipic acid, ascorbic acid, bisphenol A, camphor, dibenzofuran, 14 hexachlorobenzene, hydroquinone, ibuprofen, nicotinic acid, paracetamol, piperazine, 15 stearic acid, sorbitol, terephthalic acid and vanillin are estimated in a wide temperature 16 range with the $\mathrm{CPA}$ EoS. Generally, the modeling results are within the experimental 17 uncertainties using a single temperature independent binary interaction parameter, or a 18 solvation parameter for some non-associating solutes. Globally, an average absolute 19 deviation of $39 \%$ was obtained.

\section{Keywords: CPA, drug-like, modeling, solubility, water.}




\section{1. Introduction \\ 2}

3 Classical chemical engineering thermodynamic models such as equations of state

4 are seldomly used to obtain the aqueous solubility of drugs or drug-like molecules, either

5 because these are typically highly non-ideal systems, or the solute complexity is so high

6 that it is often impractical to determine the model parameters from the reduced data sets

7 available.

Pharmaceutical compounds are medium-size molecules from different chemical

9 families, with diverse molecular structures, typically composed of several interlinked

10 aromatic cores and multiple substituents containing heteroatoms as $\mathrm{N}, \mathrm{P}, \mathrm{O}, \mathrm{S}$, and

11 halogens. The presence of aromatic groups and electronegative heteroatoms makes these

12 molecules highly polarizable, and sometimes, conformationally flexible [1]. That flexibility

13 may affect the reactivity and solvation of the molecule, as well as possible polymorph

14 formation. This high complexity makes the prediction of their phase behavior a challenging

15 task. Thus, the thermodynamic behavior of pharmaceutical compounds is a key property in

16 drug design, as well as in the development and optimization of manufacturing processes.

17 Solubility is required in many stages of drug development. In recent years, efforts

18 have been made towards the development of predictive models to calculate the physical

19 properties and phase behavior of newly discovered active ingredients, as well as for the

20 existing ones, as available experimental data is nowadays still scarce. A brief review of the

21 excess Gibbs energy based thermodynamic models most commonly used in the

22 pharmaceutical industry was recently presented by Mota et al.[2]. 
The limitations of that type of models for high pressure and temperature phase

2 equilibria, non-ideal vapor phases as well as their need of mixture data, suggests further

3 research on the application of EoS for these systems. EoS can be used to predict solubilities

4 of complex molecules, but aqueous solubilities require that hydrogen bonding and solvation

5 effects are explicitly taken into account. The statistical associating fluid theory (SAFT) [3]

6 and the cubic-plus-association (CPA) [4-6] are two of the most successful associating EoSs.

7 These are relevant to multicomponent, multiphase equilibria of systems containing

8 associating components, but so far only PC-SAFT has been applied to pharmaceuticals [7],

9 where paracetamol, ibuprofen, sulfadiazine, $p$-hydroxyphenylacetic acid, and $p$ -

10 aminophenylacetic acid data in pure and mixed solvents were examined, as well as their

11 solubility temperature dependence. Ruether and Sadowski [7] obtained the pure component

12 and binary interaction parameters simultaneously from mixture data, and to quantitatively

13 describe the temperature dependence of the solubilities a temperature dependency on the

14 binary interaction parameter was introduced. Also, for simplicity, the heat capacity term in

15 the solid-liquid-equilibrium equation [8] was ignored, what is not always a good

16 approximation as discussed by Pappa et al. [9].

17 A recent and successful EoS is the nonrandom hydrogen bonding (NRHB) model

18 [10-11], a comprehensive lattice model combined with an EoS theory, where holes are used

19 to account for density variation as a result of temperature and pressure changes. This

20 methodology accounts explicitly for the nonrandom distribution of molecular sites, being

21 the model useful for property calculations of highly non-ideal fluids. Tsivintzelis et al. [12-

22 13] applied it to represent the phase behavior of mixtures of pharmaceuticals, namely: 
1 ibuprofen, ketoprofen, naproxen, benzoic acid, methyl paraben, ethyl paraben, N-methyl

2 aniline, acetanilide, paracetamol and phenacetin. Very satisfactory correlations were

3 obtained both in liquid or supercritical solvents, using only one regressed binary interaction

4 parameter.

5 Despite the success of the CPA EoS in predicting the phase equilibria of mixtures

6 containing a wide range of compounds, among others, hydrocarbons [14], polycyclic

7 aromatic hydrocarbons [15], fatty acids [16], and phenolic compounds [17-18], its

8 application to drug and drug-like molecules has not yet been evaluated. The model seems to

9 be promising for such molecules as many of the EoS pure component parameters can be

10 obtained from available pure component constants, such as the critical temperature and

11 pressure, and the van der Waals volume [17-18], that if not available can be accurately

12 estimated from well established group-contribution models, some of them able to

13 distinguish among isomers [19]. Additionally, some studies suggest that the cubic term

14 parameters of CPA can be correlated with the component chain length, and that similar

15 molecules present similar parameters [15-16, 20-21]. More recently, studies on

16 polifunctional phenolics solubility indicated that a group-contribution scheme can be

17 applied for the association term [17-18].

18 The aim of this work is to use CPA to model water solubilities of drug-like

19 molecules. The solubilities of acetamide, acetanilide, acetylsalicylic acid, adipic acid,

20 ascorbic acid, bisphenol A, camphor, dibenzofuran, hexachlorobenzene, hydroquinone,

21 ibuprofen, nicotinic acid, paracetamol, piperazine, stearic acid, sorbitol, terephthalic acid

22 and vanillin in water were studied. Particularly, the existence of solid-solid phase 
1 transitions and the existence of polymorphic forms were also analyzed. The molecular

2 structures of the compounds under study are presented in Fig. 1.

3 It is shown that CPA provides a good description of the aqueous solubilities for the

4 tested molecules in the complete temperature range of the available data, using a single

5 temperature independent binary interaction parameter for the majority of the systems. A

6 few non-associating compounds require an additional solvation parameter that takes into

7 account the cross-association phenomena with water.

\section{2. Thermodynamic framework}

The solubility of a solid solute in a liquid solvent is calculated by solving the

11 thermodynamic equations of equilibrium [8]. Assuming a pure solid phase, no significant

12 temperature dependence on the difference between the heat capacity of the pure liquid and

13 solid $\left(\Delta C_{\mathrm{p}}\right)$, and neglecting the effect of pressure on melting temperature $\left(T_{m}\right)$, solute

14 enthalpies of phase transition $\left(\Delta_{t r} H\right)$, and $\Delta C_{\mathrm{p}}$, the following expression is obtained:

$$
x_{s}=\frac{\varphi_{s}^{l i q_{0}}}{\varphi_{s}^{i q q}} \exp \left\{-\sum_{t r} \frac{\Delta_{t r} H}{R}\left(\frac{1}{T}-\frac{1}{T_{t r}}\right)+\frac{\Delta C_{p}}{R}\left[\frac{T_{m}}{T}-1-\ln \left(\frac{T_{m}}{T}\right)\right]\right\}
$$

18 where $x_{\mathrm{s}}$ is the solute mole fraction solubility, $R$ is the ideal gas constant, $T$ is the absolute

19 temperature, $\varphi$ is the fugacity coefficient, and subscripts 0 , $\operatorname{tr}$ and $m$ refers to a pure

20 component, a pure solute phase transition and melting, respectively. The summation in

21 equation 1 stands for the different solid-solid and fusion phase transitions of the solute. 
The CPA-EoS [6] combines the robustness and simplicity of a cubic EoS, the

2 Soave-Redlich-Kwong (SRK) or the Peng-Robinson (PR) equations, accounting for

3 physical interactions, and a chemical term from the Wertheim theory [22-23], taking into

4 account the association due to hydrogen bonding between like molecules (self-association)

5 and unlike molecules (cross-association or solvation). Polar and quadrupolar interactions

6 are not explicitly taken into consideration. The activity of each bonding site is assumed

7 independent of the other bonding sites on the same molecule. Thus, steric hindrance and

8 cooperativity effects are neglected. This association contribution, which depends on the

9 number and type of association sites, was used in other associating EoS such as SAFT [24-

10 25], and their subsequent versions [3].

11 Using a generalized cubic term, the cubic and association contributions to the

12 Helmholtz energy $(A)$ are the following $[4-5,18]$ :

$$
\begin{aligned}
A^{\text {cubic }}=\frac{a n}{b\left(\delta_{2}-\delta_{1}\right)} \ln \left(\frac{1+b \rho \delta_{1}}{1+b \rho \delta_{2}}\right)-n R T \ln (1-b \rho) \\
A^{\text {assoc }}=R T \sum_{i} n_{i} \sum_{A_{i}}\left[\ln \left(X_{A_{i}}\right)-\frac{X_{A_{i}}}{2}+\frac{1}{2}\right]
\end{aligned}
$$

15

16 where $i$ is a component index, $b$ is the covolume parameter, $a$ is the energy parameter, $\rho$ is 17 the molar density, $n$ is the number of moles, and $X_{A_{i}}$ is the mole fraction of component $i$ not 18 bonded at site $A$. If the SRK cubic term is used, $\delta_{1}$ is set equal to 1 and $\delta_{2}$ to 0 ; if, instead, 19 PR is used, $\delta_{l}$ is set equal to $1+\sqrt{2}$ and $\delta_{2}$ to $1-\sqrt{2}$. The pure component energy parameter $a$ 20 is given by a Soave-type temperature dependency, while $b$ is constant: 
3 where $a_{0}$ and $c_{1}$ are pure component parameters and $T_{r}$ is the reduced temperature. For

4 mixtures, classical van der Waals one-fluid mixing rules are employed, where a binary

5 interaction parameter $k_{i j}$ is introduced on the cross-energy parameter. For some cases, a

6 fitted cross-association volume $\beta_{i j}$ is also required in the association term, as will be

7 explained later. $X_{A_{i}}$ is the key element of the association term and is related to the

8 association strength, $\Delta^{A_{i} B_{j}}$, between two sites belonging to two different molecules, site $A$

9 on molecule $i$ and site $B$ on molecule $j$, by:

10

11

$$
X_{A_{i}}=\frac{1}{1+\rho \sum_{j} x_{j} \sum_{B_{j}} X_{B_{j}} \Delta^{A_{i} B_{j}}}
$$

13 For cross-associating systems, combining rules for the cross-association energy $\dot{\varepsilon}^{A i B j}$

14 and cross-volume $\beta^{A i B j}$ parameters (or alternatively, for the association strength) are

15 required. Different sets of combining rules have been proposed [26-29] but, in this work, 16 only the computationally simpler Elliot rule is adopted [29]:

$$
\Delta^{A_{i} B_{j}}=\sqrt{\Delta^{A_{i} B_{i}} \Delta^{A_{j} B_{j}}}
$$




$$
O F=\sum_{i}^{N P}\left(\frac{P_{i}^{\exp }-P_{i}^{c a l c}}{P_{i}^{\exp }}\right)^{2}+\sum_{i}^{N P}\left(\frac{\rho_{i}^{\exp }-\rho_{i}^{\text {calc }}}{\rho_{i}^{\exp }}\right)^{2}
$$

10 where $N P$ is the number of points, $P$ is the pressure, and the superscripts exp and calc refer 11 to experimental and calculated values, respectively.

12 For systems where solvation can occur between an associating component and a 13 non-associating one, Folas et al. [30] proposed to use the cross-association energy as half 14 the associating component association energy, and the cross-association volume as an 15 adjustable parameter, to be fitted from equilibrium data. This scheme has been successfully 16 used by several authors [14-15, 30-31]. used with the objective function: 


$$
O F=\sum_{i}^{N P}\left(\frac{x_{i}^{\exp }-x_{i}^{\text {calc }}}{x_{i}^{\exp }}\right)^{2}
$$

3 In order to compare the experimental and calculated results, absolute average 4 deviations (AAD) were used:

$$
A A D(\%)=\frac{1}{N P} \sum_{i} \frac{\left|x_{2}^{\exp }-x_{2}^{\text {calc }}\right|}{x_{2}^{\exp }} \times 100
$$

\section{Results and Discussion}

From all the compounds studied in this work, only compounds g-i in Fig. 1 are not

10 self-associating. For the other molecules, the association term in CPA was characterized by

11 the nature and number of associating groups, each of these being defined by an association

12 scheme, as proposed by Huang and Radosz [25]. The one-site (1A) scheme was used for

13 carboxylic acid groups. The two-site (2B) was used for alcohols. The three-site (3B) and

14 two-site (2B) schemes were used for primary and secondary amines, respectively.

15 Furthermore, the hydroxyl groups of ascorbic acid and sorbitol were divided into two

16 classes: in ascorbic acid they were separated into ring and aliphatic hydroxyl groups, while

17 in sorbitol the two terminal $-\mathrm{OH}$ groups were considered to be different from the other 4 .

18 Acetanilide, piperazine and paracetamol have secondary amine groups, whereas acetamide

19 has a primary amine group. The four-site (4C) association scheme was used for water [5]. 
The pure component parameters were obtained regressing vapor pressure and liquid

2 density data collected from the DIPPR database [32], from where the critical properties and

3 van der Waals volumes were also collected (Table 1). The regression was made in the

4 reduced temperature range between 0.45 and 0.85 , being also required the critical

5 temperature $\left(T_{c}\right)$ and pressure $\left(P_{c}\right)$, and the acentric factor $(\omega)$, the first to calculate the $a$

6 parameter in Eq. (4), while the others were used (simultaneously with $T_{c}$ ) to generate initial

7 estimates of the cubic term parameters. The regressed parameters are presented in Tables 1-

82 together with the water parameters from a previous work [17]. The AAD's found for

9 liquid density and vapor pressure were 1.7 and $1.8 \%$, respectively, which are good results

10 since the molecules studied are substantially more complex than those usually modeled by

11 CPA. In Fig. 2, an example of the parameter fitting to the experimental data is presented for

12 acetamide and bisphenol. Regressing the cubic parameters with $T_{c}^{2} / P_{c}\left(a_{0}\right)$ and the van der

13 Waals volume vdWV (b), like in previous works [17-18], a perfect linearity was not

14 obtained, but a correlation could be proposed for each of the parameters. In this way, the

15 cubic parameters estimated by those correlations were used as first estimates. However, the

16 results obtained turned out to be the same as without using these values as first estimates.

17 Concerning the association contribution, the association energy and volume for the

18 different associating groups involved in each molecule are presented in Table 2. No

19 tendency can be explicitly observed in these pure component parameters, since the

20 compounds do not pertain to the same family, having different structures and functional

21 groups in the same molecule. 
Some of the CPA parameters can be compared with literature values for similar

2 molecules. In Fig. 3 a comparison is made: the values obtained for acetamide, acetanilide,

3 paracetamol and piperazine are compared with those presented by Kaarsholm et al. [33] for

4 primary and secondary amines; vanillin with those of an hydroxyl group in an aromatic ring

5 in a ortho position (in relation to the aldehyde group) [17]; bisphenol A, hydroquinone and

6 paracetamol hydroxyl with phenol parameters [17]; nicotinic and terephthalic acid to those

7 of benzoic acid [17]; and the adipic and stearic acids with those published by Oliveira et al.

8 [16] for fatty acids. In general, the $\varepsilon$ values are in better agreement than the $\beta$.

9 Discrepancies in the $\beta$ parameter are expectable, since it depends more strongly on the

10 overall molecular structure, while the association energy is related to the localized

11 hydrogen bonding formation. The non-agreement found in $\varepsilon$ can be related with ring

12 substitutions that although not forming hydrogen bonds contribute for changing the polar

13 interactions.

14 Once the CPA pure component parameters are estimated, it is possible to describe

15 binary mixture properties, in this study, aqueous solubilities. Several works have been

16 published on the aqueous solubility of the studied compounds at ambient pressure, in the

17 full liquid range of water, between 273 and $373 \mathrm{~K}$ [34-49]. The required pure component

18 properties for solubility calculations (Eq. (1)) are also presented in Table 1. The fusion

19 enthalpy for nicotinic and terephthalic acids were not available in the DIPPR tables[32] and

20 so, they were obtained from the open literature [50-52]. The molar heat capacity is assumed

21 to be temperature independent, and so the presented values are calculated at $298 \mathrm{~K}$. 
Aqueous solubility data frequently presents considerable scatter [49]. Whenever

2 several points are available for each solute at the same temperature, van't Hoff plots $[\ln (x)$

3 vs. 1/T] were analyzed and the outlier points rejected. The correlations of the aqueous

4 solubility for each compound are presented in Table 3, and they were the basis to estimate

5 the $k_{i j}$ and $\beta_{i j}$. For piperazine and terephthalic acid, S-type solubility curves were found, and

6 more than one correlation equation were required.

The modeling studies of this work started in a completely predictive way, where $k_{i j}$

8 and $\beta_{i j}$ were set equal to zero. Unfortunately, only in the case of dibenzofuran acceptable

9 solubility predictions were obtained $(\mathrm{AAD}=59 \%)$. For all the other compounds, the

10 deviations were higher than $90 \%$. These deviations are not impressive because these are

11 complex molecules, with multiple functional groups, that in some cases contain ether,

12 carbonyl or ester groups that are not explicitly considered by the CPA EoS.

In order to obtain a better description of the experimental solubility data, a binary

14 interaction parameter $k_{i j}$ is required, and eventually, in the case of implicit cross-associating

15 systems (where the $2^{\text {nd }}$ component is not associating but cross-associates with water), a

16 solvation parameter $\beta_{i j}$ is also employed. Camphor, dibenzofuran and hexachlorobenzene

17 are non-self-associating, but dibenzofuran and hexachlorobenzene are able to cross-

18 associate with water. So, for these compounds, both $k_{i j}$ and $\beta_{i j}$ were estimated

19 simultaneously. For camphor, a $\beta_{i j}$ was also estimated $\left(k_{i j}=-0.19\right.$ and $\left.\beta_{i j}=0.39\right)$, but the

20 correlation results worsen, and the $\beta_{i j}$ value was too high. The estimated parameters are

21 presented in Table 4, together with the CPA deviations. An overall good description of the

22 data was obtained: an average AAD around $39 \%$ was found, with a maximum deviation of 
$168 \%$ for vanillin, where the $-\mathrm{O}-\mathrm{CH}_{3}$ group was not taken into account for associating

2 interactions. It is important to mention that for ascorbic acid the datasets presented by

3 Yalkowsky [49] and Shalmashi and Eliassi [46] show differences between 16 and 175\%,

4 proving the inherent complexities to describe such data, and thus supporting the conclusion

5 that the CPA estimates are much within the limits of the reported data. The good results

6 found for some compounds under study are presented in Fig. 4. Except for

7 hexachlorobenzene, all the $k_{i j}$ 's are negative, indicating that the water-solute interactions

8 are stronger than described by the model. The data rejected when the van't Hoff plots were

9 obtained are also plotted. This enables a better understanding about the difficulties to

10 determine these solubilities not only when modeling, but also for experimental

11 measurements.

12 To further support the importance of considering the non-ideality of these systems

13 through the use of the CPA EoS, we have also determined the ideal solubilities, where the

14 ratio of fugacity coefficients in Eq. (1) is set equal to one. Whenever ideal solution was

15 considered, extremely bad solubility predictions were obtained, with minimum deviations

16 of $70 \%$, supporting the importance of the non-ideality on the aqueous solubility estimation.

17 CPA was applied before in the description of aqueous solubilities of much simpler

18 molecules such as polycyclic aromatic compounds [15], phenolic compounds [17-18],

19 hydrocarbons [14] and fatty acids [16]. Satisfactory predictions were obtained based on a

20 single temperature independent binary parameter, with a maximum AAD of $66 \%$ for a

21 phenolic compound and, in the case of polycyclic aromatic compounds in a totally

22 predictive scheme, in average, below $60 \%$. Wide temperature and pressure ranges were 
1 tested, proving the applicability of this EoS. If a comparison is made between these results

2 and those found in this work for much more complex molecules, it can be concluded that

3 here good results were found.

4 Comparing the results obtained in this work for paracetamol with those by Mota et 5 al. [2] with the NRTL-SAC model, it can be seen that the results are of similar quality, 6 which is very good since NRTL-SAC is a correlative model based in four parameters 7 estimated from experimental data in a wide set of solvents. Excluding the acetanilide-water 8 system, for which the results are similar, the correlations found in this work are better than 9 those found with the NRHB [12-13].

10 If solid-solid transitions occur before fusion, these need to be considered in Eq. (1).

11 For nicotinic acid, there is a solid-solid transition at $452 \mathrm{~K}$, while its normal melting point 12 is $510 \mathrm{~K}$ [52]. The enthalpy of that transition is not so high $(0.8 \mathrm{~kJ} / \mathrm{mol})$, but considering it, 13 the results in the AAD are reduced, from $30 \%$ to $29 \%$. As the experimental uncertainties of 14 both enthalpies of transition are in the same order, even if the improvement in the results is 15 not so great, it can be said that the model correctly incorporates these solid-solid 16 transitions.

17 Many pharmaceutical solids and molecular crystals show polymorphism, which is 18 the ability to exhibit more than one crystalline form, displaying different thermodynamic 19 properties [53]. In fact, each polymorph should be regarded as a different solid material and 20 the control of polymorphism provides a way to tune the properties of a product. Some of 21 the compounds studied in this work were reported to have polymorphic forms. For 22 example, stearic acid has four polymorphic forms, $A, B, C$ and $E$. Form $C$ can be obtained 
1 by solidification of the melt and/or by recrystallization from a nonpolar solvent. Forms $A$

2 and $B$ when heated are transformed irreversibly into form $C$, before melting. The thermal

3 properties of polymorphic forms $B$ and $C$ were presented by Mirmehrabi and Rohani [54]:

4 the melting temperature and enthalpy of fusion of form $C$ are, respectively, $342 \mathrm{~K}$ and 68.3

$5 \mathrm{~kJ} / \mathrm{mol}$; while the transition of polymorph $B$ to $C$ occurs at $322 \mathrm{~K}$ with an enthalpy of

6 transition of $5.7 \mathrm{~kJ} / \mathrm{mol}$. Although many solid phase studies on the polymorphism of this

7 molecule have been reported, no water solubility data of each polymorph is available as a

8 function of temperature. So, only the effect of the thermal properties on the solubility

9 calculation could be evaluated, being the results only slightly different. In fact the AAD's

10 and regressed $k_{i j}$ values were not changed significantly with respect to the more stable solid

11 form $\mathrm{C}$.

12 To extend the knowledge for other equilibrium calculations, CPA is also used for

13 estimating water activity in sorbitol + water mixtures at temperatures ranging from 283 to

$14308 \mathrm{~K}$ [55]. Both with prediction and correlation $\left(k_{i j}=-0.19\right.$, the same as for solubility

15 calculations), very good results were obtained when using CPA to calculate water activities.

16 In Figure 5 is presented the results at $298 \mathrm{~K}$ where AAD of 11 and $7 \%$ were found, 17 respectively for prediction and correlation, and can be seen that estimates are improved 18 especially at lower solute concentrations.

\section{4. Conclusions}


The compounds studied in this work are complex drug-like molecules with different

3 structures and functional groups, and different abilities to associate. The CPA EoS was

4 used, for the first time, to model the aqueous solubilities of 18 of these complex molecules

5 in a wide range of temperatures. The CPA pure compound parameters were estimated

6 trough a simultaneous regression of vapor pressure and liquid density data. The global

7 deviations in vapor pressures and liquid densities were $1.8 \%$ and $1.7 \%$, respectively. The

8 hydrogen bonding behavior was also explicitly accounted for in the energy and volume

9 association parameters, with each associating group being treated individually as well as

10 multiple group substitutions considered in the association term.

11 Once the CPA parameters were obtained, phase behavior calculations could be

12 made. Pure predictions were inaccurate but if a temperature independent binary interaction

13 parameter $k_{i j}$ is estimated from experimental solubility data, the quality of the correlations

14 improve significantly. For dibenzofuran and hexachlorobenzene a solvation parameter $\beta_{i j}$,

15 is additionally required. Based on 246 experimental points, a correlation with a global AAD

16 of $39 \%$ was obtained. The CPA EoS is able to represent the solid-liquid equilibrium data of

17 drug-like molecules, proving the importance of taking into account association effects.

18 Using thermal properties of different polymorphic forms, solubility results showed

19 quite the same quality and using the same interaction parameter it was possible to represent

20 simultaneously water activity data in water + sorbitol mixtures.

21

\section{Acknowledgement}


2 The authors are grateful for the support provided by Fundação para a Ciência e a 3 Tecnologia (FCT, Lisboa, Portugal) and by LSRE financing by FEDER/POCI/2010. A.J.

4 Queimada acknowledges support from POCI/N010/2006. F.L. Mota acknowledges her FCT

5 Ph.D. scholarship SFRH/BD/32372/2006.

6

\section{$8 \quad$ List of symbols}

$9 a=$ energy parameter

$10 a_{0}=$ parameter in the cubic term $\left(\mathrm{Pa} \cdot \mathrm{m}^{6} / \mathrm{mol}^{2}\right)$

$11 A=$ Helmholtz energy $(\mathrm{J})$

$12 b=$ covolume parameter $\left(\mathrm{m}^{3} / \mathrm{mol}\right)$

$13 c_{1}=$ parameter in the cubic term

$14 k_{i j}=$ binary interaction parameter

$15 n=$ number of moles

$16 N P=$ number of data points

$17 P=$ pressure $(\mathrm{Pa})$

$18 R=$ ideal gas constant $(8.314 \mathrm{~J} /($ mol.K $))$

$19 T=$ absolute temperature $(\mathrm{K})$ 
$1 \quad v d W=$ van der Waals volume $\left(\mathrm{m}^{3} / \mathrm{mol}\right)$

$2 x=$ mole fraction

$3 \quad X_{A_{i}}=$ mole fraction of component $i$ not bonded at site A

4

$5 \quad$ Greek symbols

$6 \delta=$ specific parameters in each cubic equations

$7 \beta=$ association volume

$8 \beta_{i j}=$ solvation parameter

$9 \quad \Delta^{A i B j}=$ association strength between site $A$ on molecule $i$ and site $B$ on molecule $j$

$10 \Delta C_{\mathrm{p}}=$ difference between the heat capacity of the pure liquid and solid $(\mathrm{J} / \mathrm{mol} . \mathrm{K})$

$11 \Delta_{f u s} \mathrm{H}=$ fusion enthalpy $(\mathrm{J} / \mathrm{mol})$

$12 \varepsilon=$ association energy $(\mathrm{J} / \mathrm{mol})$

$13 \rho=$ molar density $\left(\mathrm{mol} / \mathrm{m}^{3}\right)$

$14 \varphi=$ fugacity coefficient

15

16 Subscripts

$170=$ pure component

$18 \quad c=$ critical 


$$
\begin{array}{ll}
1 & i, j, k=\text { component index } \\
2 & m=\text { melting } \\
3 & r=\text { reduced } \\
4 & s=\text { solute } \\
5 & \text { tr }=\text { transition } \\
6 &
\end{array}
$$

$7 \quad$ Superscripts

$8 \quad \operatorname{assoc}=$ association term

$9 \quad$ calc $=$ calculated

$10 \quad$ cubic $=$ cubic term

$11 \quad \exp =$ experimental

12

\section{List of abbreviations}

$14 A A D=$ absolute average deviation (\%), Eq. (9)

$15 \quad C P A=$ cubic-plus-association

$16 E o S=$ equation of state

$17 \quad O F=$ objective function

18 


\section{References}

[1] P. Kolář, J. W. Shen, A. Tsuboi,T. Ishikawa, Fluid Phase Equilib. 194 (2002) 771-782. [2] F. L. Mota, A. P. Carneiro, A. J. Queimada, S. P. Pinho,E. A. Macedo, Eur. J. Pharm. Sci. 37 (2009) 499-507.

[3] I. G. Economou, Ind. Eng. Chem. Res. 41 (2002) 953-962.

[4] G. M. Kontogeorgis, M. L. Michelsen, G. K. Folas, S. Derawi, N. von Solms,E. H. Stenby, Ind. Eng. Chem. Res. 45 (2006) 4869-4878.

9 [5] G. M. Kontogeorgis, M. L. Michelsen, G. K. Folas, S. Derawi, N. von Solms,E. H. 10 Stenby, Ind. Eng. Chem. Res. 45 (2006) 4855-4868.

11 [6] G. M. Kontogeorgis, E. C. Voutsas, I. V. Yakoumis,D. P. Tassios, Ind. Eng. Chem. Res. $12 \quad 35$ (1996) 4310-4318.

13 [7] F. Ruether,G. Sadowski, J. Pharm. Sci. 98 (2009) 4205-4215.

[8] J. M. Prausnitz, R. N. Lichtenthaler,E. G. Azevedo, Molecular Thermodynamics of Fluid-phase Equilibria,Third Prentice Hall PTR, New Jersey, 1999.

[9] G. D. Pappa, E. C. Voutsas, K. Magoulas,D. P. Tassios, Ind. Eng. Chem. Res. 44 (2005) 3799-3806.

[10] C. Panayiotou, I. Tsivintzelis,I. G. Economou, Ind. Eng. Chem. Res. 46 (2007) 26282636.

[11] I. Tsivintzelis, T. Spyriouni,I. G. Economou, Fluid Phase Equilib. 253 (2007) 19-28. 6446-6458.

[13] I. Tsivintzelis, I. G. Economou,G. M. Kontogeorgis, AlChE J. 55 (2009) 756-770.

[14] M. B. Oliveira, J. A. P. Coutinho,A. J. Queimada, Fluid Phase Equilib. 258 (2007) 5866.

[15] M. B. Oliveira, V. L. Oliveira, J. A. P. Coutinho,A. J. Queimada, Ind. Eng. Chem. Res. 48 (2009) 5530-5536.

[16] M. B. Oliveira, M. J. Pratas, I. M. Marrucho, A. J. Queimada,J. A. P. Coutinho, AlChE J. 55 (2009) 1604-1613.

[17] F. L. Mota, A. J. Queimada, S. P. Pinho,E. A. Macedo, Ind. Eng. Chem. Res. 47 (2008) 5182-5189.

[18] A. J. Queimada, F. L. Mota, S. P. Pinho,E. A. Macedo, J. Phys. Chem. B 113 (2009) 3469-3476.

[19] J. Marrero,R. Gani, Fluid Phase Equilib. 183 (2001) 183-208.

[20] M. B. Oliveira, I. M. Marrucho, J. A. P. Coutinho,A. J. Queimada, Fluid Phase Equilib. 267 (2008) 83-91.

[21] M. B. Oliveira, F. R. Varanda, I. M. Marrucho, A. J. Queimada,J. A. P. Coutinho, Ind. Eng. Chem. Res. 47 (2008) 4278-4285.

[22] M. S. Wertheim, J. Stat. Phys. 35 (1984) 19-34.

[23] M. S. Wertheim, J. Stat. Phys. 35 (1984) 35-47.

[24] W. G. Chapman, K. E. Gubbins, G. Jackson,M. Radosz, Ind. Eng. Chem. Res. 29 (1990) 1709-1721.

[25] S. H. Huang,M. Radosz, Ind. Eng. Chem. Res. 29 (1990) 2284-2294. 
[26] Y. H. Fu,S. I. Sandler, Ind. Eng. Chem. Res. 34 (1995) 1897-1909.

[27] J. Suresh,E. J. Beckman, Fluid Phase Equilib. 99 (1994) 219-240.

[28] S. J. Suresh,J. R. Elliott, Ind. Eng. Chem. Res. 31 (1992) 2783-2794.

[29] E. C. Voutsas, I. V. Yakoumis,D. P. Tassios, Fluid Phase Equilib. 158 (1999) 151-163.

[30] G. K. Folas, G. M. Kontogeorgis, M. L. Michelsen,E. H. Stenby, Ind. Eng. Chem. Res. 45 (2006) 1527-1538.

[31] M. B. Oliveira, M. G. Freire, I. M. Marrucho, G. M. Kontogeorgis, A. J. Queimada,J. A. P. Coutinho, Ind. Eng. Chem. Res. 46 (2007) 1415-1420.

[32] BYU DIPPR 801 Thermophysical Properties Database, Brigham Young University, Provo, UT, 1998.

[33] M. Kaarsholm, S. O. Derawi, M. L. Michelsen,G. M. Kontogeorgis, Ind. Eng. Chem. Res. 44 (2005) 4406-4413.

[34] A. Apelblat, E. Manzurola,N. A. Balal, J. Chem. Thermodyn. 38 (2006) 565-571.

[35] Y. Baena, J. A. Pinzón, H. J. Barbosa,F. Martínez, Phys. Chem. Liq. 42 (2004) 603613.

[36] P. Bustamante, S. Romero, A. Peña, B. Escalera,A. Reillo, J. Pharm. Sci. 87 (1998) 1590-1596.

18 [37] M. Davies,D. M. L. Griffiths, Trans. Faraday Soc. 49 (1953) 1405-1410.

[38] L. C. Garzón,F. Martínez, J. Solution Chem. 33 (2004) 1379-1395.

[39] J. A. Jiménez,F. Martínez, J. Braz. Chem. Soc. 17 (2006) 125-134.

[40] J. H. Li, B. X. Zhou,W. M. Cai, J. Chem. Eng. Data 52 (2007) 2511-2513.

[41] X. N. Li, Q. X. Yin, W. Chen,J. K. Wang, J. Chem. Eng. Data 51 (2006) 127-129.

[42] T. S. Logan, J. Am. Chem. Soc. 67 (1945) 1182-1184.

[43] A. Noubigh, M. Cherif, E. Provost,M. Abderrabba, J. Chem. Eng. Data 53 (2008) $1675-1678$.

[44] A. Noubigh, A. Mgaidi, M. Abderrabba, E. Provost,W. Furst, J. Sci. Food Agric. 87 (2007) 783-788.

[45] A. Seidell, J. Am. Chem. Soc. 29 (1907) 1091-1095.

[46] A. Shalmashi,A. Eliassi, J. Chem. Eng. Data 53 (2008) 1332-1334.

30 [47] W. Y. Shiu, F. Wania, H. Hung,D. Mackay, J. Chem. Eng. Data 42 (1997) 293-297.

31 [48] L. C. Wang,F. A. Wang, J. Chem. Eng. Data 49 (2004) 155-156.

[49] S. H. Yalkowsky,Y. He, Handbook of Aqueous Solubility Data, ed. 1, CRC Press, New York, 2003.

[50] J. P. Coelho, K. Bernotaityte, M. A. Miraldes, A. F. Mendonça,R. P. Stateva, J. Chem. Eng. Data 54 (2009) 2546-2549.

[51] D. Q. Li, J. C. Liu, D. Z. Liu,F. A. Wang, Fluid Phase Equilib. 200 (2002) 69-74.

[52] NIST Chemistry Webbook in Vol. National Institute of Standards and Technology (NIST): Gaitherburg, MD, NJ, 2007.

[53] H. G. Brittain, Polymorphism in Pharmaceutical Solids, Informa Health Care, New York, 1999.

[54] M. Mirmehrabi,S. Rohani, Can. J. Chem. Eng. 82 (2004) 335-342.

[55] L. Ninni, M. S. Camargo,A. J. A. Meirelles, J. Chem. Eng. Data 45 (2000) 654-660.

[56] Z. Kolská, J. Kukal, M. Zábranský,V. Růžička, Ind. Eng. Chem. Res. 47 (2008) 20752085. 
[57] B. T. Goodman, W. V. Wilding, J. L. Oscarson,R. L. Rowley, J. Chem. Eng. Data 49 (2004) 24-31.

3

4

5 
1 Table 1. Pure component properties [32, 50-52], cubic CPA parameters and AAD's

2 for vapor pressure and liquid densities.

\begin{tabular}{|c|c|c|c|c|c|c|c|c|c|c|}
\hline \multirow[b]{2}{*}{ Compound } & \multirow[b]{2}{*}{$\begin{array}{l}\mathrm{Tc} \\
(\mathrm{K})\end{array}$} & \multirow[b]{2}{*}{$\begin{array}{l}\mathrm{Tm} \\
(\mathrm{K})\end{array}$} & \multirow[b]{2}{*}{$\begin{array}{c}\Delta_{\mathrm{fus}} \mathrm{H} \\
(\mathrm{kJ} / \mathrm{mol})\end{array}$} & \multirow[b]{2}{*}{$\begin{array}{c}\Delta \mathrm{C}_{p} \\
(\mathrm{~J} / \mathrm{mol} \mathrm{K})\end{array}$} & \multirow[b]{2}{*}{$\begin{array}{l}v d W \times 10^{5} \\
\left(\mathrm{~m}^{3} / \mathrm{mol}\right)\end{array}$} & \multicolumn{3}{|c|}{ CPA cubic term parameters } & \multicolumn{2}{|c|}{$\operatorname{AAD}(\%)$} \\
\hline & & & & & & $\begin{array}{c}\mathrm{a}_{0} \\
\left(\mathrm{~Pa} \mathrm{~m}^{6} / \mathrm{mol}^{2}\right)\end{array}$ & $\mathrm{c}_{1}$ & $\begin{array}{c}\mathrm{b} \times 10^{5} \\
\left(\mathrm{~m}^{3} / \mathrm{mol}\right)\end{array}$ & $P$ & $\rho$ \\
\hline Acetamide & 761 & 354 & 15.71 & 51.58 & 3.57 & 1.92 & 0.91 & 5.54 & 1.3 & 2.2 \\
\hline Acetanilide & 825 & 388 & 21.65 & 1.92 & 7.93 & 4.37 & 1.17 & 12.25 & 3.8 & 1.9 \\
\hline Acetylsalicylic acid & 765 & 408 & 25.60 & 26.55 & 9.17 & 4.62 & 1.48 & 13.56 & 0.1 & 2.3 \\
\hline Adipic acid & 809 & 426 & 34.85 & 108.07 & 8.00 & 4.80 & 1.49 & 12.48 & 1.3 & 2.4 \\
\hline Ascorbic acid & 783 & 465 & 29.20 & 81.40 & 8.10 & 3.79 & 2.96 & 11.94 & 3.4 & 2.2 \\
\hline Bisphenol A & 849 & 430 & 29.29 & 170.22 & 13.5 & 6.14 & 2.19 & 20.06 & 2.0 & 1.2 \\
\hline Camphor & 709 & 452 & 6.82 & 92.78 & 9.69 & 4.49 & 0.87 & 14.64 & 0.6 & 0.1 \\
\hline Dibenzofuran & 824 & 355 & 19.29 & 39.74 & 8.66 & 5.14 & 0.94 & 14.28 & 1.1 & 1.7 \\
\hline Hexachlorobenzene & 825 & 502 & 25.52 & 111.79 & 10.7 & 4.84 & 1.42 & 14.13 & 1.3 & 0.7 \\
\hline Hydroquinone & 823 & 445 & 27.11 & 55.19 & 5.94 & 2.20 & 1.27 & 10.37 & 3.7 & 0.7 \\
\hline Ibuprofen & 765 & 349 & 25.61 & 149.74 & 12.8 & 7.33 & 1.37 & 20.47 & 3.9 & 2.1 \\
\hline Nicotinic acid & 760 & 510 & 26.70 & 32.93 & 6.27 & 3.38 & 1.25 & 10.33 & 0.2 & 1.3 \\
\hline Paracetamol & 736 & 441 & 27.70 & 32.14 & 8.44 & 3.45 & 1.76 & 15.96 & 0.4 & 0.5 \\
\hline Piperazine & 638 & 379 & 11.70 & 5.24 & 5.71 & 2.25 & 1.29 & 10.61 & 0.5 & 1.6 \\
\hline Stearic acid & 804 & 343 & 61.21 & 116.84 & 19.7 & 12.22 & 1.58 & 33.47 & 3.2 & 2.1 \\
\hline Sorbitol & 868 & 365 & 32.00 & 28.08 & 9.58 & 4.82 & 2.34 & 12.72 & 3.7 & 2.7 \\
\hline Terephthalic acid & 1113 & 700 & 63.43 & $44.23^{\mathrm{a}}$ & 8.28 & 5.16 & 1.33 & 10.91 & 0.7 & 3.6 \\
\hline Vanillin & 777 & 355 & 15.60 & 50.72 & 8.14 & 4.12 & 1.43 & 12.63 & 0.3 & 1.7 \\
\hline Water & 647 & 273 & 6.00 & & 1.24 & 0.12 & 0.67 & 1.45 & 1.3 & 0.6 \\
\hline
\end{tabular}

$5{ }^{\text {a }}$ Calculated using a group-contribution method for the estimation of the heat capacities of 6 liquids [56] and a correlation based on molecular structure for the heat capacity of solids 7 [57]. 
1 Table 2. Association parameters in the CPA EoS.

\begin{tabular}{lccc}
\hline Compound & $\begin{array}{c}\varepsilon \\
(\mathrm{kJ} / \mathrm{mol})\end{array}$ & $\beta$ & Group \\
\hline Acetamide & 13.4 & $2.99 \times 10^{-3}$ & $\mathrm{NH}_{2}$ \\
acetanilide & 3.74 & $1.00 \times 10^{-1}$ & $\mathrm{NH}$ \\
Piperazine & 3.57 & $1.00 \times 10^{-1}$ & $\mathrm{NH}$ \\
Acetylsalicylic acid & 11.4 & $1.68 \times 10^{-4}$ & $\mathrm{COOH}$ \\
Adipic acid & 18.5 & $3.45 \times 10^{-4}$ & $\mathrm{COOH}$ \\
Ibuprofen & 1.10 & $9.61 \times 10^{-4}$ & $\mathrm{COOH}$ \\
Nicotinic acid & 4.40 & $7.33 \times 10^{-3}$ & $\mathrm{COOH}$ \\
Stearic acid & 42.2 & $4.10 \times 10^{-5}$ & $\mathrm{COOH}$ \\
Terephthalic acid & 35.4 & $9.20 \times 10^{-3}$ & $\mathrm{COOH}$ \\
& 14.9 & $9.08 \times 10^{-3}$ & $\mathrm{OH}$ ring \\
Ascorbic acid & 14.7 & $4.10 \times 10^{-5}$ & $\mathrm{OH}$ aliphatic \\
Bisphenol A & 19.2 & $1.54 \times 10^{-3}$ & $\mathrm{OH}$ \\
Hydroquinone & 19.2 & $2.38 \times 10^{-2}$ & $\mathrm{OH}$ \\
Sorbitol & 18.6 & $1.68 \times 10^{-5}$ & $\mathrm{OH}$ aliphatic \\
& 21.4 & $5.54 \times 10^{-3}$ & $\mathrm{OH}$ terminal \\
Vanillin & 7.82 & $3.87 \times 10^{-2}$ & $\mathrm{OH}$ \\
Paracetamol & 6.45 & $5.48 \times 10^{-2}$ & $\mathrm{NH}$ \\
Water & 17.9 & $2.06 \times 10^{-2}$ & $\mathrm{OH}$ \\
\hline & 16.6 & $8.90 \times 10^{-2}$ & $\mathrm{OH}$ \\
\hline
\end{tabular}


1 Table 3. Correlations of the experimental aqueous solubility data for the compounds

2 under study: $\ln (x)=\mathrm{A} / T+\mathrm{B}$.

3

\begin{tabular}{lcccc}
\hline Compound & $\mathrm{A}$ & $\mathrm{B}$ & $\mathrm{R}^{2}$ & Refs. \\
\hline Acetamide & -552.1 & 0.140 & 0.989 & {$[49]$} \\
Acetanilide & -3232.3 & 3.703 & 0.988 & {$[35-36,42,45,49]$} \\
Acetylsalicylic acid & -2948.9 & 2.171 & 0.994 & {$[49]$} \\
Adipic acid & -4800.4 & 10.303 & 0.987 & {$[37,49]$} \\
Ascorbic acid & -1773.3 & 2.240 & 0.994 & {$[46,49]$} \\
Bisphenol A & -2613.9 & -1.598 & 0.984 & {$[40,49]$} \\
Camphor & -992.2 & -5.494 & 0.941 & {$[49]$} \\
Dibenzofuran & -4074.7 & -0.817 & 0.992 & {$[47,49]$} \\
Hexachlorobenzene & -4359.3 & -7.185 & 0.969 & {$[47,49]$} \\
Hydroquinone & -3916.6 & 8.803 & 0.987 & {$[41]$} \\
Ibuprofen & -3672.4 & -1.326 & 0.952 & {$[38,49]$} \\
Nicotinic acid & -2458.5 & 2.329 & 0.982 & {$[48-49]$} \\
Paracetamol & -3142.5 & 4.252 & 0.983 & {$[35-36,39,49]$} \\
Piperazine & $-3238.2^{\mathrm{a}} ;-418.59^{\mathrm{b}}$ & $7.532^{\mathrm{a}} ;-0.770^{\mathrm{b}}$ & $0.953^{\mathrm{a}} ; 0.991^{\mathrm{b}}$ & {$[49]$} \\
Stearic acid & -1540.2 & -10.296 & 0.988 & {$[49]$} \\
Sorbitol & -537.7 & -0.923 & 1.000 & {$[49]$} \\
Terephthalic acid & $3961.8^{\mathrm{c}} ;-964.6^{\mathrm{d}} ;$ & $-25.442^{\mathrm{c}} ;-8.616^{\mathrm{d}} ;$ & $0.983^{\mathrm{c}} ; 0.919^{\mathrm{d}} ;$ & $0.986^{\mathrm{e}}$ \\
Vanillin & $-2458.2^{\mathrm{e}}$ & $-3.978^{\mathrm{e}}$ & 0.965 & \\
\hline & -4522.2 & 8.413 & $0.49]$ \\
\hline
\end{tabular}

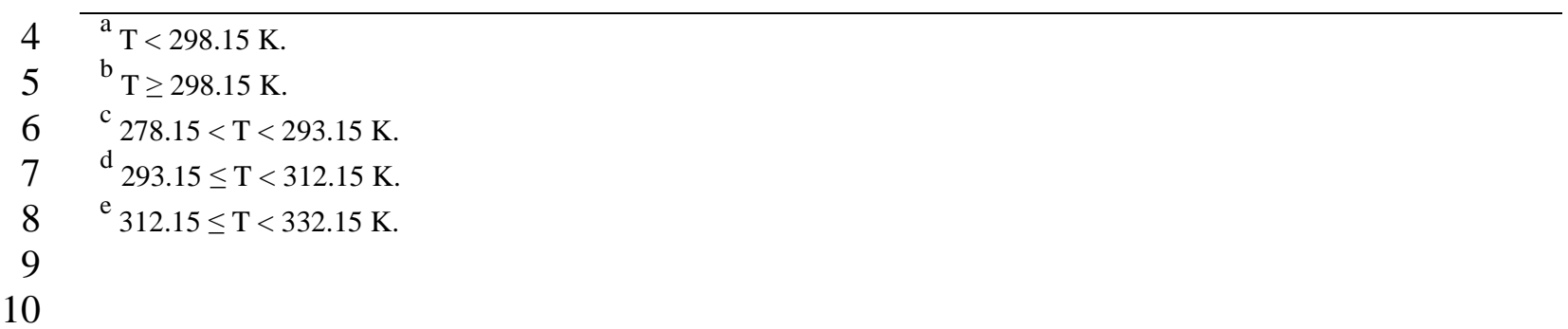


1 Table 4. CPA modeling results and respective binary interaction and cross-volume 2 parameters.

\begin{tabular}{|c|c|c|c|c|}
\hline Compound & $k_{i j}$ & $\beta_{i j}$ & $\operatorname{AAD}(\%)$ & $\mathrm{RMSD}^{\mathrm{a}}$ \\
\hline Acetamide & -0.079 & - & 44.1 & 0.24 \\
\hline Acetanilide & -0.099 & - & 12.9 & 0.08 \\
\hline Acetylsalicylic acid & -0.151 & - & 15.8 & 0.08 \\
\hline Adipic acid & -0.110 & - & 60.7 & 0.63 \\
\hline Ascorbic acid & -0.184 & - & 45.4 & 0.32 \\
\hline Bisphenol A & -0.111 & - & 34.8 & 0.21 \\
\hline Camphor & -0.252 & - & 19.5 & 0.10 \\
\hline Dibenzofuran & -0.025 & 0.001 & 25.6 & 0.10 \\
\hline Hexachlorobenzene & 0.144 & 0.014 & 38.8 & 0.23 \\
\hline Hydroquinone & -0.209 & - & 43.2 & 0.34 \\
\hline Ibuprofen & -0.140 & - & 18.7 & 0.10 \\
\hline Nicotinic acid & -0.197 & - & 35.5 & 0.17 \\
\hline Paracetamol & -0.210 & - & 32.8 & 0.12 \\
\hline Piperazine & -0.248 & - & 55.8 & 0.48 \\
\hline Stearic acid & -0.267 & - & 63.9 & 0.47 \\
\hline Sorbitol & -0.190 & - & 34.6 & 0.23 \\
\hline Terephthalic acid & -0.197 & - & 52.5 & 0.53 \\
\hline Vanillin & -0.091 & - & 68.0 & 0.25 \\
\hline
\end{tabular}

$4 \quad$ a $R M S D=\sqrt{\frac{\sum_{i=1}^{n}\left(\ln x_{i, c a l c}-\ln x_{i, \exp }\right)^{2}}{n}}$ 
Figure Captions:

3 Fig. 1. Molecular structure of: (a) acetamide, (b) acetanilide, (c) acetylsalicylic acid, (d) 4 adipic acid, (e) ascorbic acid, (f) bisphenol A, (g) camphor, (h) dibenzofuran, (i) 5 hexachlorobenzene, (j) hydroquinone, (k) ibuprofen, (l) nicotinic acid, (m) paracetamol, (n) 6 piperazine, (o) stearic acid, (p) sorbitol, (q) terephthalic acid and (r) vanillin.

8 Fig. 2. Performance of the CPA EoS in the correlation of (a) liquid density and (b) vapor 9 pressure of acetamide $(\bullet)$ and bisphenol $(\mathbf{\Delta})$ :- - CPA; ---, DIPPR correlation.

11 Fig. 3. Comparison between associating parameters obtained for the molecules under study $12\left(\Delta\right.$, acetamide; $\mathrm{x}$, acetanilide; $\downarrow$, adipic acid; ${ }^{\circ}$, acetylsalicylic acid; $\circ$, bisphenol $\mathrm{A} ;+$, 13 hydroquinone; •, ibuprofen; -, nicotinic acid; $\bullet$, paracetamol; $\mathbf{-}$, piperazine; $\boldsymbol{\Delta}$, stearic 14 acid; $\diamond$, terephthalic acid; $\square$, vanillin) and similar molecules: (a) $\varepsilon$ and (b) $\beta$. The 15 superscript $*$ refers to the same associative group in different molecules.

17 Fig. 4. Aqueous solubilities of some compounds under study: experimental $(\bullet$, acetamide; 18 ○, acetylsalicylic acid; $\diamond$, bisphenol A; +, camphor; $x$, dibenzofuran; $\square$, hydroquinone; $\mathbf{\nabla}$, 19 hexachlorobenzene; $\diamond$ nicotinic acid; $\mathbf{\square}$, terephthalic acid) and CPA results (-).

21 Fig. 5. Water activity in aqueous sorbitol solutions at $298.15 \mathrm{~K}$ ( $\diamond$, experimental [55]; and 22 CPA results: ---, prediction; - , correlation). 


\section{$1 \quad$ Figure 1:}

2<smiles>CC(N)=O</smiles>

(a)

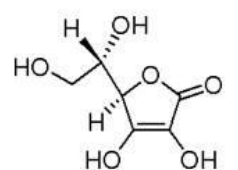

(e)<smiles>Oc1ccc(O)cc1</smiles>

(j)

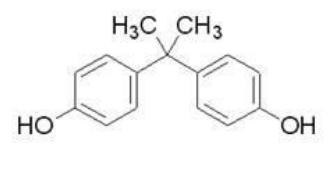

(f)

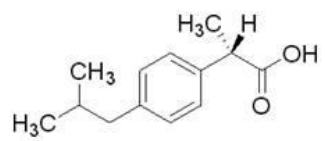

(k)

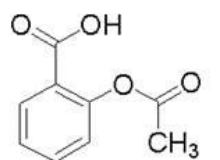

(c)

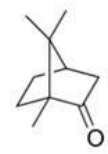

(g)<smiles>CC(O)C1CCCCC1</smiles>

(l)<smiles>[3H]C([3H])C([3H])C([3H])C(C)CC</smiles>

(p)

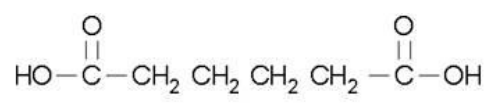

(d)

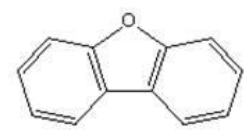

(h)

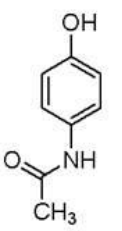

(m)<smiles>O=C(O)c1ccc(C(=O)O)cc1</smiles>

(q)

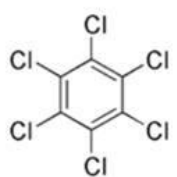

(i)

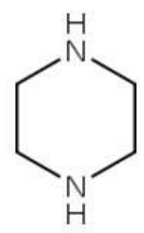

(n)

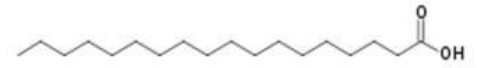

(o)

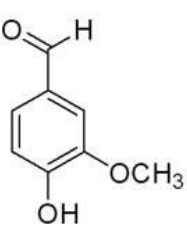

(r) 
1 Figure 2:

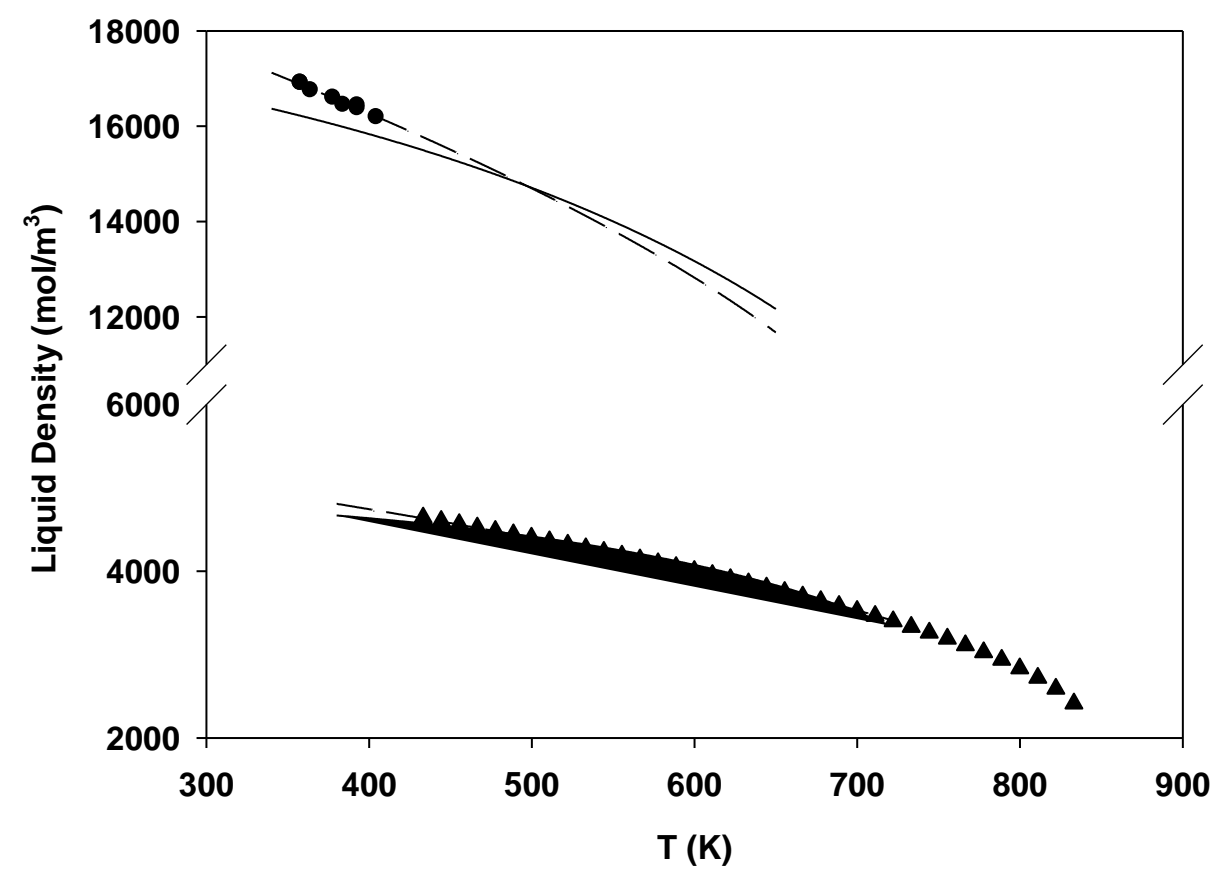

3
4

(b)

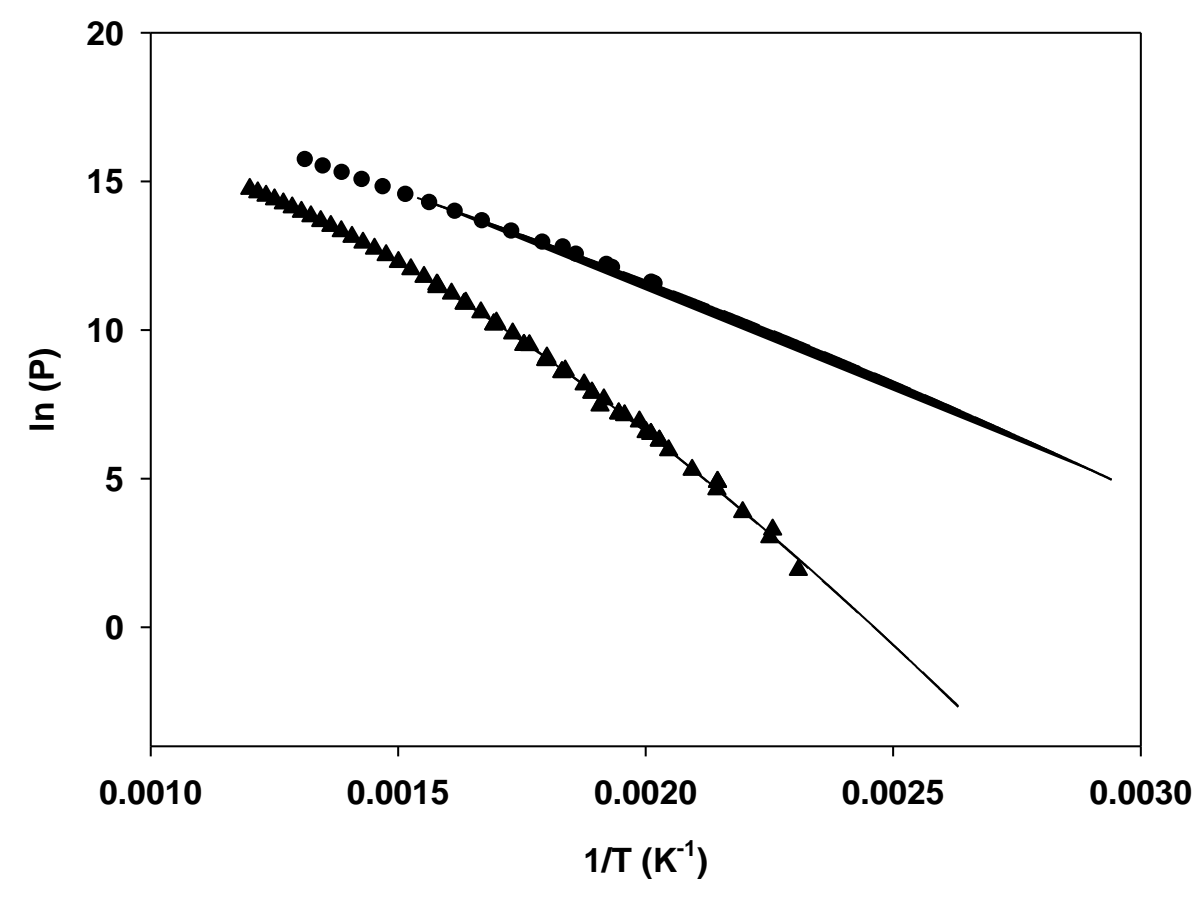




\section{Figure 3:}

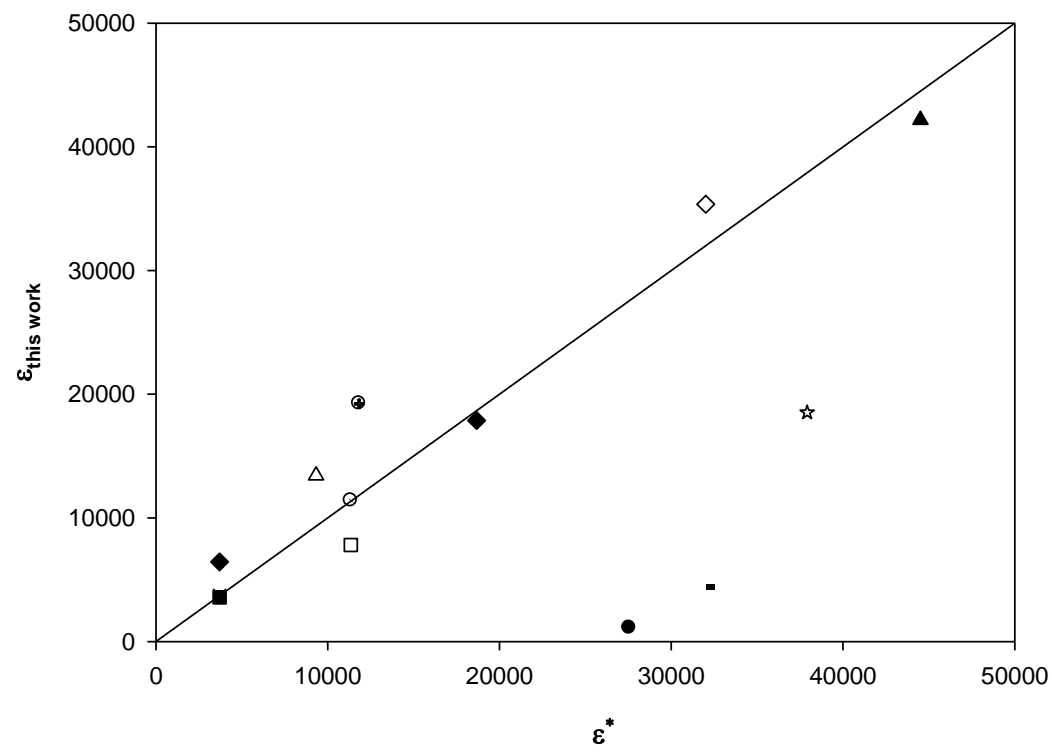

3

(a)

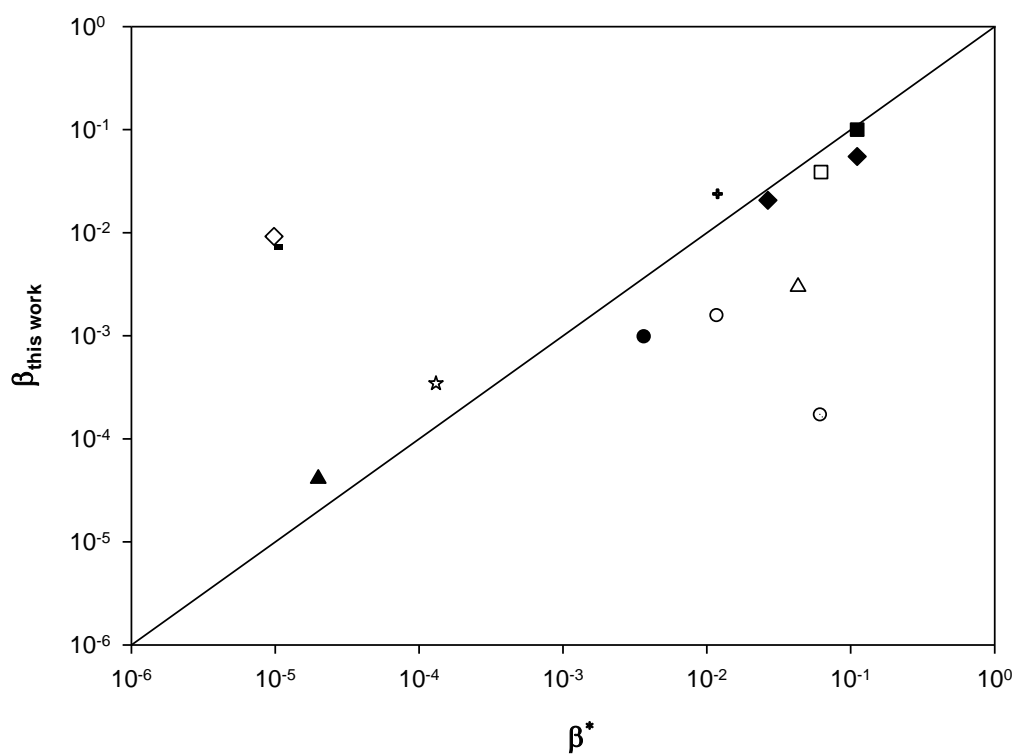

5

(b) 
$1 \quad$ Figure 4:

2

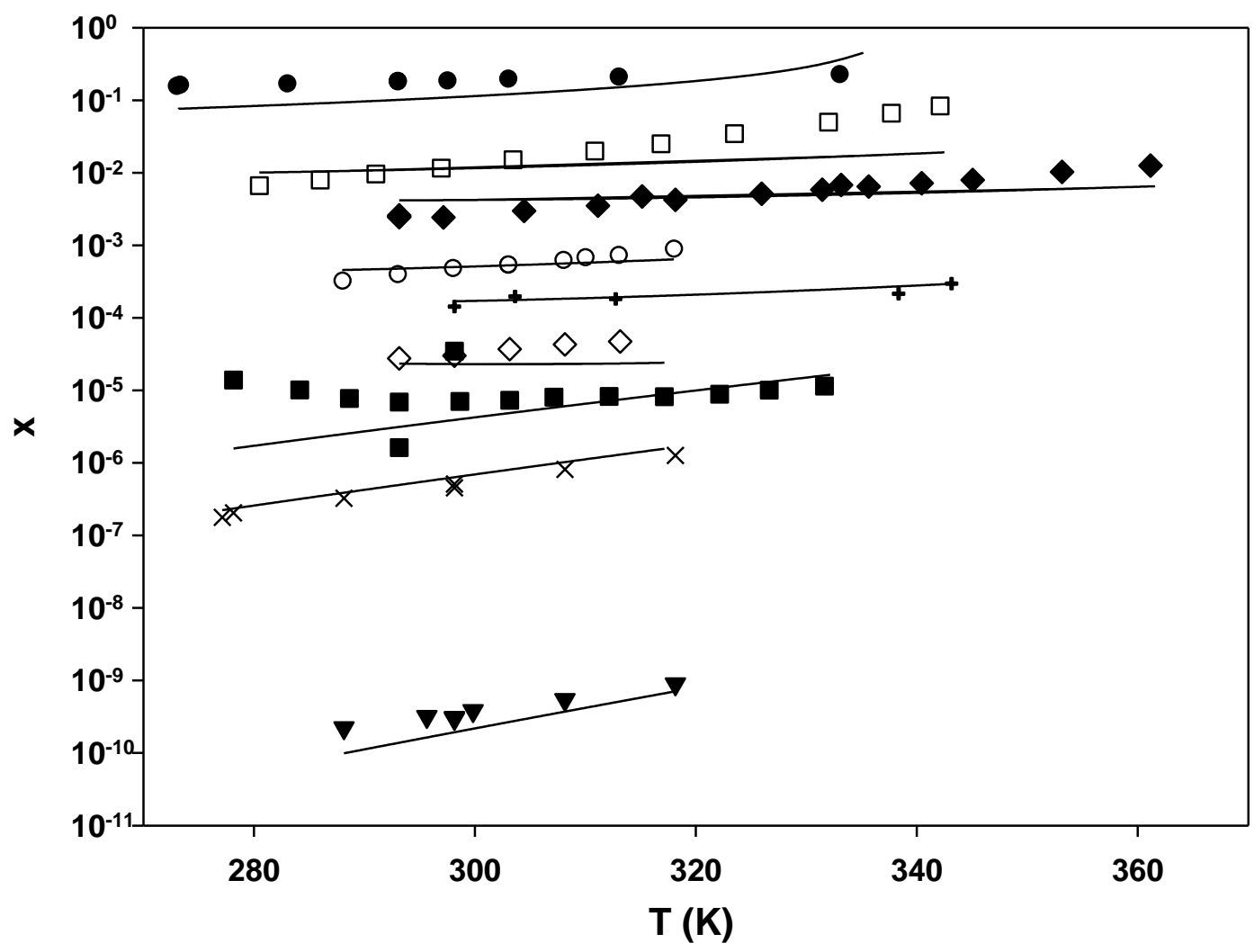

4 
1 Figure 5:

2

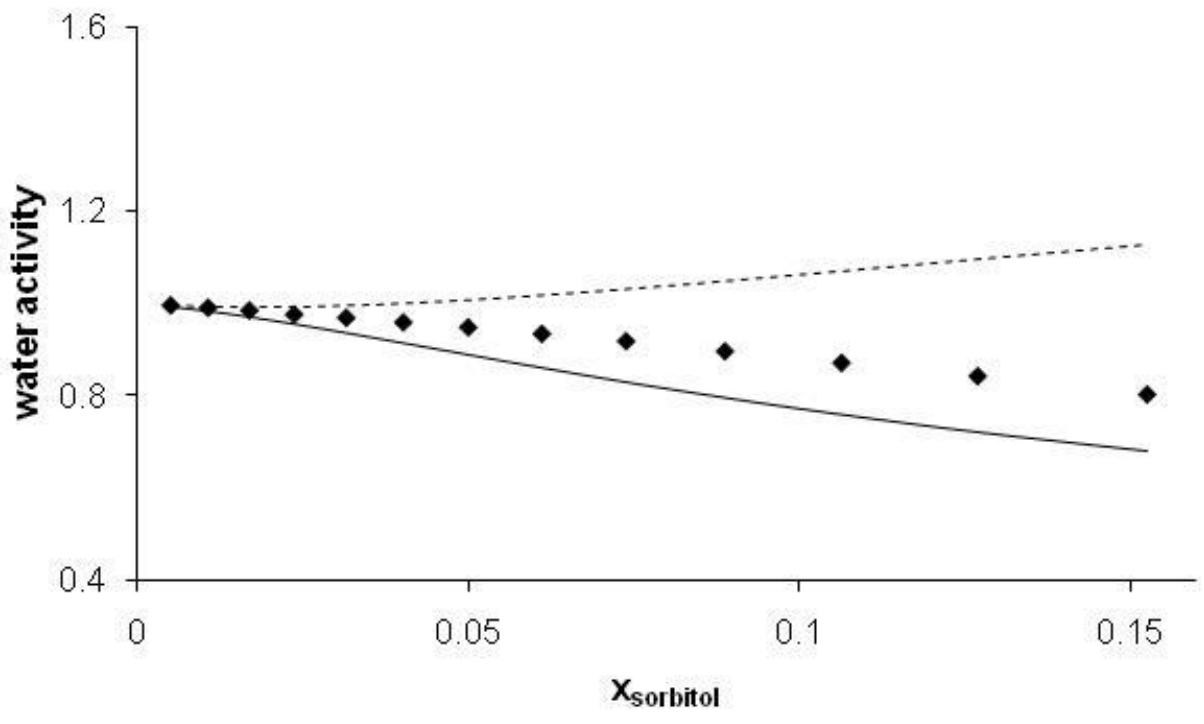

3 